\title{
천해역에 위치한 바지형 부유체의 계류시스템 설계 The Design Development on the Mooring System of a Floating Barge Positioned in the Shallow Water Zone
}

\author{
김영복* \\ Young-Bok Kim*
}

\begin{abstract}
요 지 : 본 연구는 험한 해양환경하에서 천해역에 떠 있는 부유체 해양양식장의 동적 거동 해석기법을 연구하 기 위해 시도되었다. 본 연구의 내용은 양식장의 설치 위치를 연안이 아닌 근해지역으로 옮겼을 때 파도의 영 향과 함께 계류라인이 해저면에 설치된 영향, 즉 해저면의 영향이 많은 영향을 미칠 것이라는 타 논문에서 발 표된 사실을 밝히기 위해 수치해석 프로그램을 개발한 내용이며, 이를 통해 천해역에 설치된 계류라인과 해양 양식장을 모형화한 부유체 바지의 연성된 동적 응답해석을 수행할 때 해저면의 강성을 고려할 수 있는 프로그 램을 확보하게 되었다.
\end{abstract}

핵심용어 : 해양양식장, 계류된 부유체, 계류삭 장력, 천해역, 해저면 영향, 부유체 동적 거동

\begin{abstract}
This study is aimed to develop the dynamic analysis technique for a floating aquaculture in a shallow water region under the harsh sea condition. In case of the installation region to transform from a coastal area to the offshore area, the influence of sea bed with sea waves on the mooring lines was announced to be significant by other authors. In this study, the numerical tool was developed to solve dynamic behavior of the floating barge coupled with mooring lines in a shallow zone of the sea considering the influence of sea bed on the floating system.
\end{abstract}

Keywords : floating barge; Moored body; Mooring tension; Shallow water; Sea bed; Dynamic behavior

\section{1. 서 론}

최근 이십여년 동안에 전세계적으로 양식업은 식품시장에 서 중요한 역할을 담당하여 왔다. 중국에서는 전통적인 어업 에 의한 어획량 보다 양식에 의한 어획량이 더 많은 지역도 있다고 보고되고 있다. 유럽은 스칸디나비아 반도 국가들을 중심으로 해양 양식장의 연구와 재생가능한 친환경적인 해양 농장의 개념을 실현하는 연구를 계속하고 있다. 핀란드의 경 우는 전국적으로 이와 같은 해양 양어장이 수개나 있으며 이 들 양어장에는 연구기능을 같이 가지고 있어 해양양식장에 적 합한 어종에 관한 연구를 처음 부화된 알로부터 치어에 이르 기까지 실시하여 효과적인 양어법을 지역 특성에 맞게 개발 해가고 있다 (참조: http://www.rktl.fi/english/aquaculture/ aquaculture_stations /laukaa_fish_farm.html(2013.10.10.)). 스웨덴에서는 2007 년도부터 $\mathrm{EU}$ 의 지원으로 $\mathrm{KRAV}$ 프로젝트 를 통해 양식에 적합한 어종과 양식장에서 나오는 어류들의 배설을 친환경적으로 이용하는 연구를 하고 있다. 노르웨이 는 북해 피오르드식 해안을 따라 천해의 연안지역을 활용하 여 연어 양식을 성공리에 추진하고 있다.
근래에 와서는 해양공간을 효과적으로 이용하려는 노력의 일환으로 연안 보다는 조금 더 떨어진 해역에 천해역에 양식 장으로 활용하기 위한 부유체를 설치하려는 시도가 스칸디나 비아 반도 삼국인 핀란드, 스웨덴과 노르웨이, 그리고 북남미 대륙의 칠레와 미국 하와이 등지에서 시도되고 있다. 우리나 라에도 제주도 해역에서 시험적으로 이와 같은 시도가 진행 되고 있다. 이러한 시도는 폭우기 연안지역에 발생하는 적조 등의 해양오염으로 인한 양식업의 피해를 근원적으로 차단하 기 위한 수단으로 강구되고 있는 중이다. 양식을 위한 부유 체는 이전의 가두리 양식장의 크기 보다는 훨씬 큰 규모를 가 지고 있는 것이 보통이며, 해양구조물을 응용한 계류된 부유 체의 형상을 가지고 있게 된다. 이와 같은 근해에 설치할 해 양양식장을 제작하고 운영하기 위해서는 먹이를 육상에서 제 법 떨어져 있는 양식장까지 나르고, 성어를 육지로 이송하기 위한 공급선과 근해에 부유된 양식장의 구조물에 대해 예상 되는 극한환경 하에서도 계류 및 운동 안정성이 확보되어야 한다.

본 연구는 근해에 설치될 해양양식장을 바지형태로 단순화 하고 해상조건을 Sea-state 6 9까지로 가정하여 비교적 천해

*경남대학교 조선해양IT공학과(Naval Architecture, Ocean \& IT Engineering Department, Kyungnam University, 7 Kyungnam University-ro, MasanHappo-gu, Changwon, Kyungnam, 631701, Korea, Tel:+82-55-249-2718, Fax:+82-0505-999-2168, ybkim-1@kyungnam.ac.kr) 
역에 설치될 것을 가정하고, 해양양식장을 부유체로 수치모 델화하여 동적 안전성해석 방법을 찾아보는 연구를 한 것이 다. 이를 통해 향후 해상양식장이 해상에서 계류 중이거나 이 동 시에 운동 안전성 확보에 관한 연구에 활용하고자 하였으 며, 실제 이를 해양자원 개발에 적용한다면 해양 산업분야에 또 하나의 새로운 신성장동력 산업분야를 창출할 수 있게 될 것으로 기대한다.

\section{2. 대상 부유체의 제원과 환경조건}

\section{1 부유체의 제원 및 계류라인 배치}

단순화된 형태로 가정된 해양양식장의 제원은 Table 1과 같 고, 그 형상은 Fig. 1과 같다.

Table 1 중 $\mathrm{Cb}$ 는 방형비척계수이고, $\mathrm{KG}$ 는 바지선 밑바닥 부터 무게중심점까지의 거리를 의미한다. 박상기 Fig. 1은 구 조물 모델링을 위한 프로그램인 PATRAN(2008)을 이용하여 부유체의 해수와의 접수면 만을 모델링한 결과로서 절점과 사 각형 또는 삼각형 2차원 요소의 수가 각각 2217개와 2144개 이다. 이 부유체를 해상에 계류하기 위한 라인 설치는 Fig. 2 와 같이 각 코너의 하단부에 3 라인씩을 $45^{\circ}$ 를 기준으로하여 $\pm 5^{\circ}$ 씩 벌려서 설치하였으며 그 형상은 Fig. 2 와 같다.

고박을 위해 배치된 계류라인의 길이는 $50 \mathrm{~m}, 60 \mathrm{~m}, 80 \mathrm{~m}$,

Table 1. Principal dimensions of a floating barge of the simplified offshore aquaculture

\begin{tabular}{|c|c|c|}
\hline \multicolumn{2}{|c|}{ Item } & Dimensions \\
\hline \multicolumn{2}{|c|}{ Deadweight } & 2,460 ton \\
\hline \multicolumn{2}{|c|}{ LBP(Length Between Perpendicular) } & $30.0 \mathrm{~m}$ \\
\hline \multicolumn{2}{|c|}{ Breadth } & $20.0 \mathrm{~m}$ \\
\hline \multicolumn{2}{|c|}{ Depth } & $6.0 \mathrm{~m}$ \\
\hline \multicolumn{2}{|c|}{ Draft(design) } & $4.0 \mathrm{~m}$ \\
\hline \multicolumn{2}{|c|}{$\mathrm{Cb}$} & 1.0 \\
\hline \multicolumn{2}{|c|}{$\mathrm{KG}$} & $1.2 \mathrm{~m}$ \\
\hline \multirow{3}{*}{$\begin{array}{l}\text { Radius of } \\
\text { gyration }\end{array}$} & $\mathrm{Kxx}$ & $8.0 \mathrm{~m}$ \\
\hline & Kyy & $7.2 \mathrm{~m}$ \\
\hline & Kzz & $7.2 \mathrm{~m}$ \\
\hline
\end{tabular}

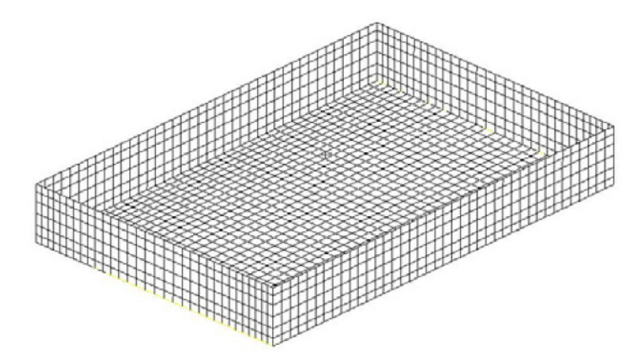

Fig. 1. Configuration of a floating barge of the simplified offshore aquaculture.
$100 \mathrm{~m}, 150 \mathrm{~m}$ 로 5 가지 조건으로 계류라인 설치각도(fairlead angle $)=51.3^{\circ}$ 로 펼쳐서 해저 바닥에 앵커로서 고정시키도록 설치했다고 가정한다. 부유체의 설치 방향은 바람이 불어 들 어오는 방향과 일치시키도록 하여 바람의 영향을 최소화시키 도록 배치한다. 계류라인의 특성치는 Table 2 와 같다.

상기 Table 2에서 $\mathrm{CI}$ 는 관성계수로서 구조물과 유체입자로 구성된 시스템에 관성력을 유발시키는 계수값이고, $\mathrm{CD}$ 는 유 체의 점성저항에 의한 저항력을 유발시키는 저항계수이다.

\section{2 해상조건}

근해역은 대개 천수지역이며 해양파가 연안으로 밀려올거 나 밀려나갈 때 파도가 부서지면서 해저면에 미치는 효과로 천수효과가 나타나는 지역일 가능성이 높다. 또한 이러한 천 수지역에 설치되었다가 유사시 극한 환경하에서는 피항할 것 도 대비하여야 하는 부유체 구조물이 되어야 할 것이다. 하 지만 본 연구에서는 특정 지역인 제주도와 육지 사이의 천해 역에 설치될 때의 경우에 대해서 동적거동 안정성을 검토할 예정이므로 극한환경 중 파도와 바람에 대한 해상조건을 Sea state 7로 Table 3에 정리된 해상조건을 설정하였다.

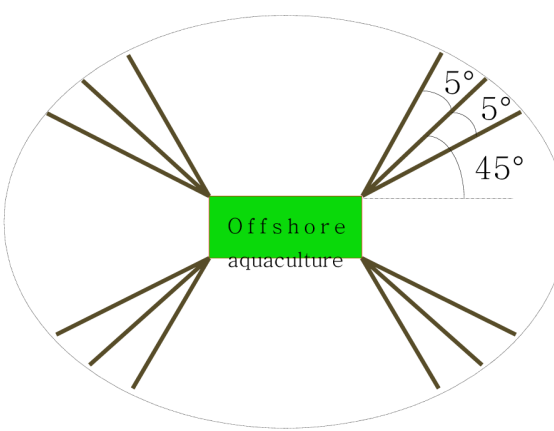

(a) plan view

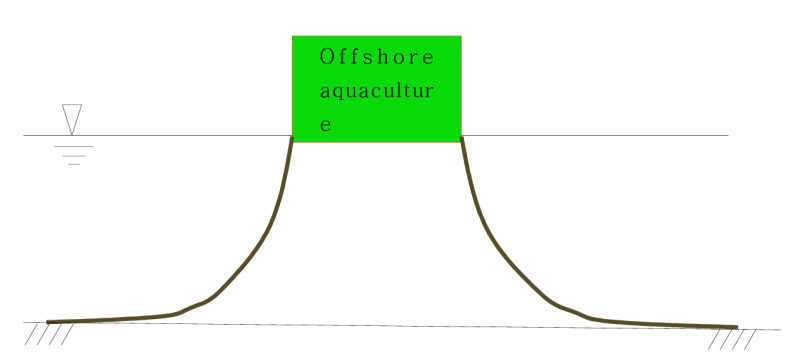

(b) sheer plan view

Fig. 2. Outlines of the mooring line arrangement for mooring barge.

Table 2. Properties of mooring lines

\begin{tabular}{cccccc}
\hline \hline \multirow{2}{*}{ Items } & $\begin{array}{c}\text { Stiffness } \\
(\mathrm{EA})\end{array}$ & $\begin{array}{c}\text { Dry } \\
\text { weight }\end{array}$ & $\begin{array}{c}\text { Displaced } \\
\text { weight }\end{array}$ & $\mathrm{CI}$ & $\mathrm{CD}$ \\
\cline { 2 - 6 } & $\mathrm{N}$ & $\mathrm{kg} / \mathrm{m}$ & $\mathrm{kg} / \mathrm{m}$ & $\mathrm{N} / \mathrm{m}$ & $\mathrm{N} / \mathrm{m}$ \\
\hline $\begin{array}{c}\text { Mooring line } \\
\text { for a floating } \\
\text { barge }\end{array}$ & $1.01 \mathrm{E}+09$ & 129.0 & 15.71 & 34.48 & 130.0 \\
\hline
\end{tabular}


Table 3. Selected sea state conditions

\begin{tabular}{ccccccc}
\hline \hline \multirow{2}{*}{$\begin{array}{c}\text { Sea } \\
\text { State }\end{array}$} & \multicolumn{2}{c}{ Significant Wave } & \multicolumn{2}{c}{ Modal Wave } & \multicolumn{2}{c}{$\begin{array}{c}\text { Sustained Wind } \\
\text { Number }\end{array}$} \\
\cline { 2 - 6 } & Reight(m) & \multicolumn{2}{c}{ Period(sec) } & \multicolumn{2}{c}{ Speed(knots) } \\
\hline 6 & $4 \sim 6$ & 5 & $10.0-18.7$ & 12.4 & $28-47$ & 37.5 \\
7 & $6 \sim 9$ & 7.5 & $11.7-19.8$ & 15 & $48-55$ & 51.5 \\
8 & $9 \sim 14$ & 11.5 & $14.5-21.5$ & 16.4 & $56-63$ & 59.5 \\
$>8$ & $>14$ & $>14$ & $16.4-22.5$ & 20 & $>63$ & $>63$ \\
\hline
\end{tabular}

Table 4. Stiffnesses of seabed according to the regions

\begin{tabular}{cc}
\hline \hline item & $\begin{array}{c}\text { Stiffness of seabed } \\
\text { (dynamic viscosity) }\end{array}$ \\
\cline { 2 - 3 }$\left[\mathrm{N} \cdot \mathrm{s} / \mathrm{m}^{2}\right]$ \\
\hline region 1 & $7.0 \mathrm{E}+06$ \\
region 2 & $1.0 \mathrm{E}+07$ \\
region 3 & $4.0 \mathrm{E}+07$ \\
region 4 & $7.0 \mathrm{E}+07$ \\
region 5 & $1.0 \mathrm{E}+08$ \\
region 6 & $1.5 \mathrm{E}+08$ \\
\hline
\end{tabular}

조류는 선수방향으로 입사할 경우를 고려하고, 이때의 속 도를 $2 \mathrm{~m} / \mathrm{s}$ 로 일정하게 전 해저 깊이에 걸쳐 흐르는 것으로 가정한다. 또한 부유체와 조우하는 파도와 조류의 방향은 같 은 방향으로 일치하는 것으로 가정하고, 그 방향은 부유체의 선미를 기준으로 $67.5^{\circ}$ 에서 입사하는 것으로 한다. 해저면 바 닥의 강성은 Table 4 와 같이 가정하여 각각의 조합에 따른 동 적 해석을 수행하였다.

\section{3. 이 론}

해저면의 전단강도와 투과성 그리고 거칠기 등은 해저면 위 의 모든 파도의 특성에 영향을 준다. 이와 같은 해저면과의 상호작용은 파랑감쇠와 파도 운동학상 국부적인 변화를 일으 키는 것으로 알려져 있다. 만일 해저면 위의 파도가 해저면 에 묻혀있는 파이프라인, 라이저 또는 계류라인에 큰 변형과 응력을 유발한다면 이와 연결되어 있는 부유체에 큰 영향을 미치게 될 것이다. 점성유체의 지배방정식인 Navier-Stokes 방 정식의 선형화된 형태는 다음 식과 같다.

$$
\begin{aligned}
& \frac{\partial u}{\partial t}=-\frac{1}{\rho} \frac{\partial p}{\partial x}+v\left(\frac{\partial^{2} u}{\partial x^{2}}+\frac{\partial^{2} u}{\partial z^{2}}\right) \\
& \frac{\partial w}{\partial t}=-\frac{1}{\rho} \frac{\partial p}{\partial z}+v\left(\frac{\partial^{2} w}{\partial x^{2}}+\frac{\partial^{2} w}{\partial z^{2}}\right)-g
\end{aligned}
$$

여기서, $u$ 는 수평방향인 $x$ 방향 유체입자 속도이고, $w$ 는 수직 방향인 $z$ 방향 유체입자속도이다. 또한 $p$ 는 고려되는 유체입 자가 놓여 있는 위치에서의 수압이며, $\rho$ 는 유체의 밀도, $v$ 는 유체의 동점성계수, $g$ 는 중력가속도를 의미한다. 비회 전류와 회전류를 나누어서 $x$ 방향 속도 만을 고려하면,

$$
u=u_{p}+u_{r}
$$

로 주어진다. 여기서 $u_{p}$ 는 비회전류, $u_{r}$ 은 회전류에서의 속 도를 의미한다. $u_{p}$ 는 Euler 방정식을 만족하므로

$$
\frac{\partial u_{p}}{\partial t}=-\frac{1}{\rho} \frac{\partial p}{\partial x}
$$

이 되고, 나머지부분은 오더(order)로 보면 다음식과 같이 쓸 수 있다.(Dean \& Dalrymple(1991))

$$
\frac{\partial u_{r}}{\partial t} \approx v \frac{\partial^{2} u_{r}}{\partial z^{2}}
$$

라고 할 수 있다. 일반적으로 식 (4)의 값은 식 (5)의 값에 비 해 매우 작은 것으로 알려져 있다.

한편 Newton의 전단응력항은 다음 식으로 얻어진다.

$$
\tau_{x z}=\left.\rho v\left(\frac{\partial u}{\partial z}+\frac{\partial w}{\partial x}\right)\right|_{z=-h}
$$

여기서 $\tau_{x z}$ 는 해저면의 전단응력이며, $h$ 는 수심이고, 따라서 $z=-h$ 는 해저면을 의미한다. 크기로 보면 식 (6)에서 첫째 항만이 크므로 식 (6)은 다음과 같이 쓸 수 있다.

$$
\left.\tau_{x z} \approx \rho v\left(\frac{\partial u}{\partial z}\right)\right|_{z=-h}
$$

앞에서 유도된 식 (5)와 (7)로부터 $\boldsymbol{x}$ 방향의 속도 구배는 그 위치에서의 유체 가속도를 $z$ 축에 관해 1 차 적분하면 얻을 수 있고, 이 값에 $z=-h$ 인 값을 얻어 다시 $\rho$ 를 곱해주면 해 저면의 전단응력을 얻을 수 있다는 것을 알 수 있다. 이를 해 저면을 따라 또는 계류라인이 접한 면적을 따라 적분해 부면, 해저바닥에 묻혀져 있는 계류라인에 걸리는 전단력을 구할 수 있다.

상기에서 유도된 식을 부유체 바지선의 운동과 연결한 운 동방정식은 다음 식과 같다.

$$
\left[M+M^{\alpha}(\infty)\right] \ddot{\zeta}+k \zeta=F_{I}(t)+F_{c}(\dot{\zeta}, t)+F_{m}(\dot{\zeta}, t)
$$

여기서 $M$ 은 구조물의 질량이며, $M^{\alpha}(\infty)$ 는 구조물 주위의 유 체에 의한 부가수질량을 나타내며, 이때 $(\infty)$ 로 표현된 것은 모든 구조물의 주파수 영역에서 상수임을 뜻한다. 따라서 일 정한 주파수 $\omega$ 일때의 부가수질량인 $M^{\alpha}(\omega)$ 의 항과 같이 쓰 면 $M^{\alpha}(\infty)=M^{\alpha}(\omega)-\int_{0}^{\infty} R(t) \cos \omega t d t$ 로 구해진다. 여기서 $R(t-\tau)$ 는 지연함수(retardation function)라고 하는 파도의 진행속도와 구조물의 속도차이를 고려하기 위한 함수이다. 또 한 $\zeta$ 는 구조물의 변위이며, $\dot{\zeta}$ 는 구조물의 속도, $\ddot{\zeta}$ 는 가속 
도를 의미한다. $K$ 는 구조강성이며, 우변은 외력에 해당하는 성분력인데 첫째항 $F_{I}(t)$ 는 입사파 포텐셜에 의한 외력이며, 둘째항 $F_{c}(\dot{\zeta}, t)$ 는 간섭되는 파도의 영향을 고려한 상호갑섭 에 의한 포텐셜항으로 $F_{c}(\zeta, t)=\int_{-\infty} R(t-\tau) \zeta(\tau) d \tau$ 의 적분식을 통해 얻어지며 항이다. 우변의 세 번째 식은 모리슨 힘(Dean, R. G. \& Dalrymple, R. A. (1991))이라고 불리는 힘이며 다 음 식으로 표현되는 외력성분이다.

$$
F_{m}(\zeta, t)=C_{m} \rho \forall u_{n}-C_{a} \rho \forall \xi_{n}+\frac{1}{2} \rho C_{D} D_{s}\left(u_{n}-\zeta_{n}\right)\left|u_{n}-\zeta_{n}\right|
$$

여기서 $C_{m}=1+C_{a}$ 는 관성계수이며, $C_{a}$ 는 부가수질량계수 이다. 또한 $\ddot{u}_{n}$ 은 유체입자가속도이고, $\forall$ 는 구조물의 체적 이다. $\rho$ 는 유체밀도이고, $C_{D}$ 는 저항계수, $D_{s}$ 는 구조물과 유 체운동에 영향을 미치는 구조물에 대한 유체입자 상대속도 로 인해 발생하는 저항계수이다.

이상의 운동방정식은 부유체 구조물에 걸리는 외력성분을 구한 것이고, 이 구조물에 설치된 계류라인과 연성된 운동은 별도의 운동방정식을 유도하여 라이저 동해석 방정식을 유도 해야 한다. 실제로 본 연구에서도 해수에 의한 외력성분은 포 텐셜 이론에 따라 BEM(Boundary Element Equation)을 이용 하여 수치해석적으로 풀었고, 계류라인은 부유체 운동과 연성 시켜 별도의 라이저 동해석 방정식을 유도하여 보이론을 적용 한 FEM(Finite Element Method) 기법을 이용하여 수치해석적 으로 풀었다. 부유체 구조물과 라인 연성 동해석방정식을 선 형이론에 따라 계류라인을 굽힘강성을 가진 보요소로 치환하 여 보와 부유체를 연성하여 유도한 운동방정식은 다음과 같다.

$$
\begin{aligned}
& -\left(E I r^{\prime \prime}\right)^{\prime \prime}+\left(\lambda r^{\prime}\right)^{\prime}+q=\rho_{r} \ddot{r} \\
& \frac{1}{2}\left(r^{\prime} \bullet r^{\prime}-1\right)=\frac{T}{E A} \approx \frac{\lambda}{E A}
\end{aligned}
$$

여기서 $E I$ 는 굽힘강성이다. 이중 는 Young's Modulus 값이 고, $I$ 는 계류라인의 관성모멘트 값이다. 또한, $\rho_{r}$ 은 라인의 밀도를 나타내며, $r$ 은 라인의 한 요소의 위치벡터이고, $\ddot{r}$ 은 가속도를 나타낸다. $r^{\prime}$ 의 '는 계류라인의 호선길이 $s$ 로 위 치벡터 $\mathrm{r}$ 을 일차미분한 값이며, $r^{\prime \prime}$ 는 이차미분한 값이다. 이 식에서 $\lambda$ 는 Lagrangian multiplier라고 불리는 수치해석 수 렴오차를 최소화하고 수렴속도를 빠르게 하기 위한 가상의 큰 수이다. $q=w+F^{s}+F^{d}$ 는 라인에 미치는 외력성분을 나타낸 다. 이중에서 $w$ 는 라인의 길이당 무게이며, $F^{s}$ 는 라인에 걸 리는 유체정역학적 힘, 즉 부력과 수심에 따른 수두력이고, $F^{d}$ 는 라인에 걸리는 모리슨 힘으로 다음 식으로 주어진다.

$$
F^{d}=-C_{A} \ddot{r}^{n}+C \dot{V^{n}}+C_{D}\left|V^{n}-\dot{r^{n}}\right|\left(V^{n}-\dot{r}^{n}\right)+A_{p} \rho v\left(V^{n}\right)^{\prime}
$$

여기서, $C_{A}$ 는 라인 주변의 유체에 의한 부가수질량 계수이며, $C_{M}$ 은 관성계수이고, $C_{D}$ 는 점성저항계수이다. $r^{n}$ 은 라인 요
소의 위치벡터의 라인에 수직한 벡터성분이고, 따라서 $r^{n}$ 은 가 속도 성분이다. $V^{n}$ 는 유체입자의 라인 수직성분 속도이고, $\dot{V}^{n}$ 는 유체가속도이다. $A_{p}$ 는 라인의 길이를 따른 전단면적, 즉 요소길이 방향으로 투영된 단면적이며, $\rho$ 와 $v$ 는 앞에서 설 명한 유체밀도와 바닥의 효과를 고려한 동점성계수이다.이 마 지막 항이 해저면의 점성효과로 인한 전단력을 고려하는 항 이다. 해저면의 동점성계수는 실험을 통해서 얻어질 수 있으 나, 본 논문에서는 다른 연구(Keoje Big Island, PFV Ltd. Co. (2014))에서 이용한 해저면 점성계수를 적용하여 계산하 였다.식(12)에서 계산한 외력을 식(10)과 (11)에 대입하여 구 조물에 대한 식 (8)과 연성으로 풀게되면 계류라인의 동적거 동을 해석할 수 있게 된다.

\section{4. 조합된 해석조건}

앞 절에서의 가정된 해상조건과 해역에 따른 해저면 강성 을 고려하여 조합한 수치해석 시나리오는 Table 5와 같다.

해석조건 중 case 3 의 계류라인 길이와 해저면 강성은 해석 조건 1과 2의 결과를 보고 적합한 값으로 정한 결과이다. 즉, 계류라인 길이는 기면 길수록 장력이나 부유체 운동 측면에서 유리하므로 고려 조건 중 가장 긴 $150 \mathrm{~m}$ 로 하였으며, 해저면의 점성계수는 다른 천해역의 해저바닥 점성계수(Keoje Big Island PFV Ltd. (2013))를 적용하였으며, 이 값은 본 논문에

\begin{tabular}{|c|c|c|c|c|c|}
\hline \multirow[t]{2}{*}{ cases } & \multirow[t]{2}{*}{ sea state } & \multicolumn{2}{|c|}{ water depth $\begin{array}{c}\text { mooring } \\
\text { line length }\end{array}$} & \multirow{2}{*}{$\begin{array}{c}\begin{array}{c}\text { seabed } \\
\text { stiffness }\end{array} \\
\mathrm{N} \cdot \mathrm{s} / \mathrm{m}^{2}\end{array}$} & \multirow[t]{2}{*}{ remarks } \\
\hline & & $\mathrm{m}$ & $\mathrm{m}$ & & \\
\hline \multirow{5}{*}{1} & \multirow{5}{*}{7} & 40 & 50 & $2.1 \mathrm{E}+06$ & \multirow{5}{*}{$\begin{array}{l}\text { the } \\
\text { line } \\
\text { length } \\
\text { effect }\end{array}$} \\
\hline & & 40 & 60 & $2.1 \mathrm{E}+06$ & \\
\hline & & 40 & 80 & $2.1 \mathrm{E}+06$ & \\
\hline & & 40 & 100 & $2.1 \mathrm{E}+06$ & \\
\hline & & 40 & 150 & $2.1 \mathrm{E}+06$ & \\
\hline \multirow{5}{*}{2} & \multirow{5}{*}{7} & 40 & 150 & $1.8 \mathrm{E}+06$ & \multirow{5}{*}{$\begin{array}{c}\text { the } \\
\text { seabed } \\
\text { stiffness } \\
\text { effect }\end{array}$} \\
\hline & & 40 & 150 & $5.0 \mathrm{E}+06$ & \\
\hline & & 40 & 150 & $1.0 \mathrm{E}+07$ & \\
\hline & & 40 & 150 & $5.0 \mathrm{E}+07$ & \\
\hline & & 40 & 150 & $1.0 \mathrm{E}+08$ & \\
\hline \multirow{7}{*}{3} & \multirow{7}{*}{7} & 20 & 150 & $2.1 \mathrm{E}+06$ & \multirow{7}{*}{$\begin{array}{c}\text { the } \\
\text { shallow } \\
\text { water } \\
\text { effect }\end{array}$} \\
\hline & & 30 & 150 & $2.1 \mathrm{E}+06$ & \\
\hline & & 40 & 150 & $2.1 \mathrm{E}+06$ & \\
\hline & & 50 & 150 & $2.1 \mathrm{E}+06$ & \\
\hline & & 60 & 150 & $2.1 \mathrm{E}+06$ & \\
\hline & & 80 & 150 & $2.1 \mathrm{E}+06$ & \\
\hline & & 100 & 150 & $2.1 \mathrm{E}+06$ & \\
\hline
\end{tabular}
서 고려하는 지역의 해저면에 적용하는 것이 적합하다고 판 단되는 값으로 결정하였다. 앞 절에서 부유체의 유체역학적

Table 5. Analysis senarios 
특성치를 구하기 위한 프로그램으로는 Newman(1998)을 이 용하였으며, 계류시스템의 동해석을 위해서는 $\mathrm{Kim}(2003)$ 에 사 용된 프로그램을 해저면 효과를 계산할 수 있도록 일부 개선 하였다.

\section{5. 해석 결과}

동적 해석은 상기에서 설명한 해석조건에 대해 바람은 API RP 2T(1997) 규정을 이용하여 돌풍의 스펙트럼(gust wind spectrum)으로 취급하여 시간역 풍력을 별도 프로그램에서 구

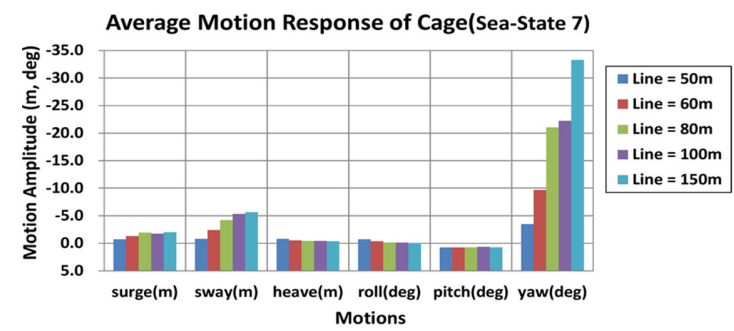

(a) average responses

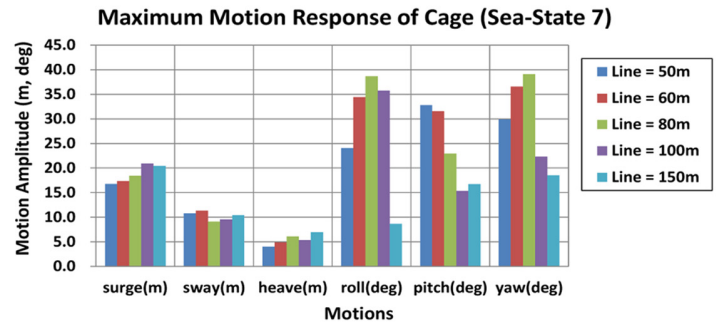

(c) max. responses

Fig. 3. Motion responses of the barge (Case 1).

Average of Mooring Line Tensions (Sea-State 7)

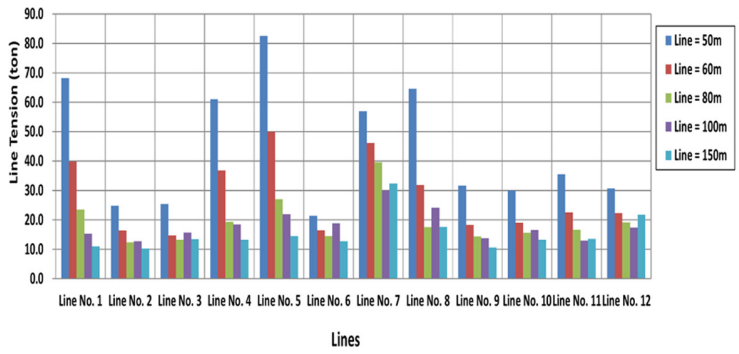

(a) average tensions

Maximum Mooring Line Tensions (Sea-State 7)

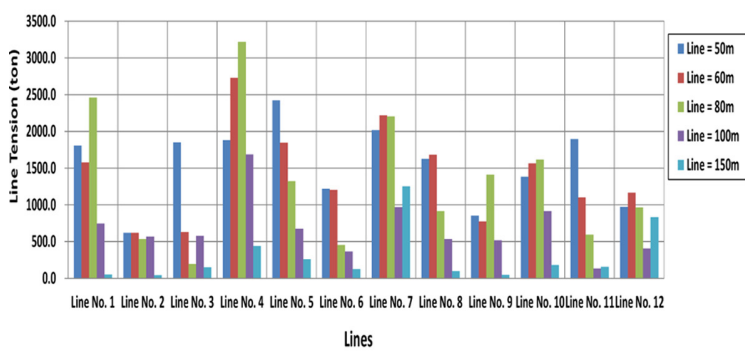

(c) max. tensions
하여 입력자료로 준비한다. 파랑하중과 조류력은 본 동해석 프로그램 내부에서 계산하도록 되어 있는데, 본 연구에서는 파랑하중에 대하여는 수정된 Pierson-Moskowitz spectrum으 로 가정하여 해석조건에 따라 Sea state 7에 맞는 유의파고 와 피크주기를 입력하여 주고, 조류력은 OCIMF(1997)의 지 침서에 따라 수정된 값을 유조선에 유사한다고 가정하여 수 정된 계수 값을 입력해 줌으로써 프로그램 내부에서 계산하 도록 하였다. 해저면의 강성은 유한요소로 나누어진 각 라인 요소에 동점성계수로 고려하여야 하나 이 값은 실험을 통해 서 만이 얻을 수 있는 특성 값으로 외부에서 입력할 수 있

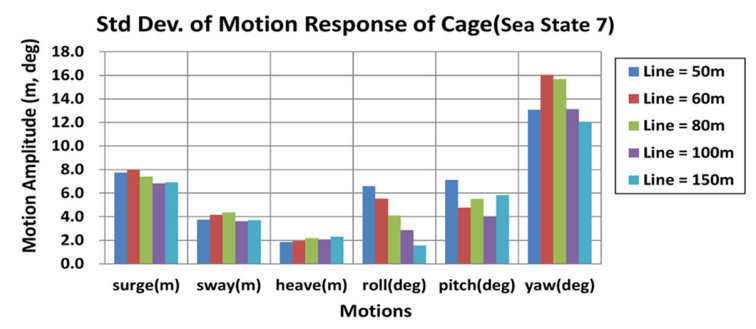

(b) std. dev. responses

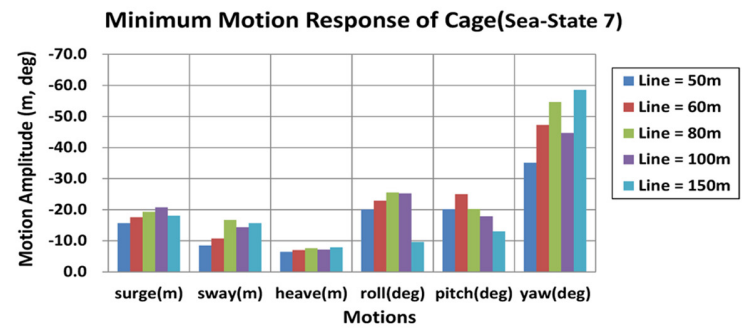

(d) min. responses

\section{Standard Deviation of Mooring Line Tensions (Sea-State 7)}

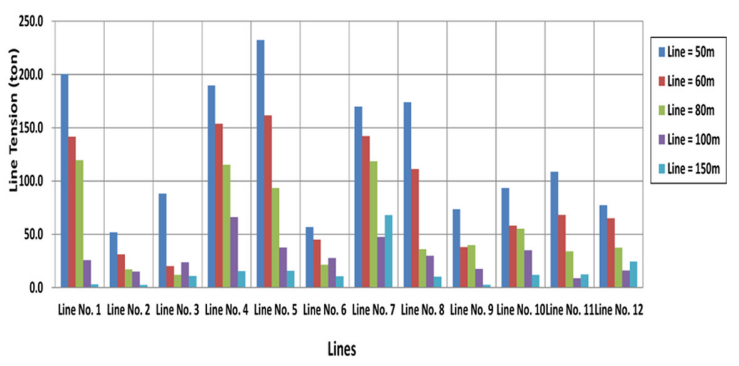

(b) std. dev. tensions

Minimum Mooring Line Tensions (Sea-State 7)

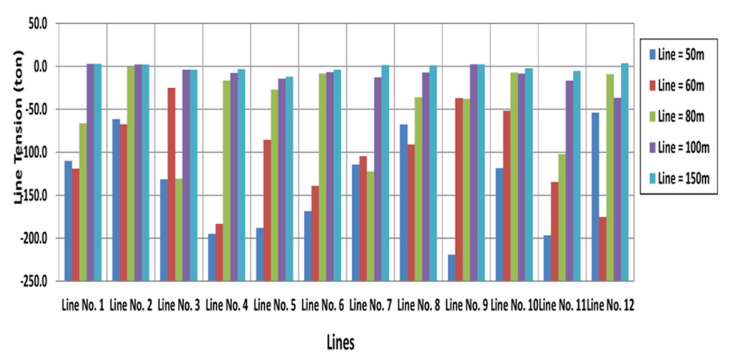

(d) min. tensions

Fig. 4. Mooring line tensions of the barge (Case 1). 
도록 프로그램을 개선하였다. 해석은 시간역에서 수행되며 시 간간격은 0.005 초 이고 총 2150 초(약 30 분간)동안 해석을 수 행하였으며, 해석결과의 비교를 위해 통계분석한 자료를 Fig. 3 8에 보였다.

Fig. 3과 4는 Sea state 7에서 계류라인의 길이를 $50 \mathrm{~m}$ 부터 $150 \mathrm{~m}$ 까지 변화시켜가며 천해역에 부유체를 계류했을 때의 효 과를 본 것이다. 해석결과에서 보면 계류라인이 길수록 부유체 의 운동이나 계류라인의 장력에 있어 평균값에서는 불리하지 만 대체적으로 다른 값에서는 유리하다는 것을 알 수 있다. 따 라서 이후의 해석조건 시나리오에 의한 해석, 즉 case 2 4의 해

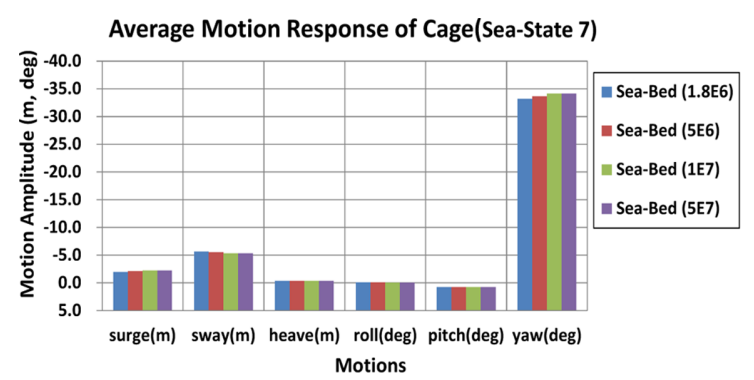

(a) average responses

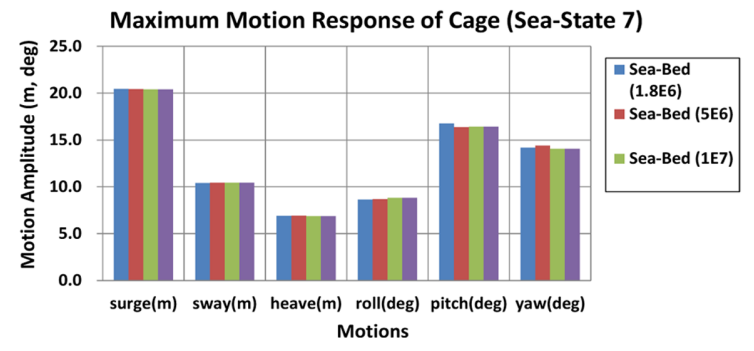

(c) max. responses

Fig. 5. Motion responses of the barge (Case 2).

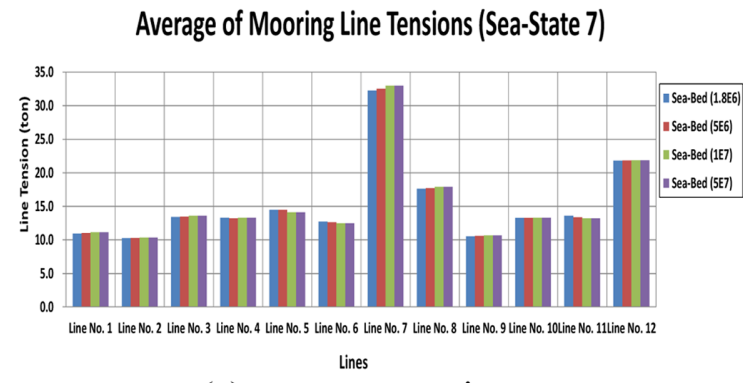

(a) average tensions

Maximum Mooring Line Tensions (Sea-State 7)

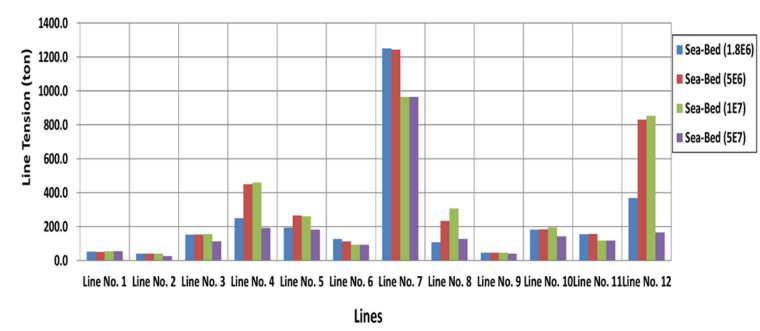

(c) max. tensions
석은 계류라인의 길이를 $150 \mathrm{~m}$ 로 유지하여 계산을 수행하였다.

해석조건 case 2 의 경우는 해저면의 강성을 고려하여 적 절할 강성을 선정하기 위한 비교 해석이었다. 대략적인 해 저면의 강성은 Keoje Big Island PFV Ltd. Co.(2014)에서 참고하였는데, 이 문헌에 의하면 해저면의 전단강도의 변형 계수가 대략 $1.8 \mathrm{E}+07 \sim 4.5 \mathrm{E}+08 \mathrm{~N} / \mathrm{m}^{2}$ 의 범위의 값인데 본 연구에서 사용한 계류라인의 지름이 $0.1 \mathrm{~m}$ 이므로 단위길이 당 스프링 계수는 변형계수 값에 0.1 을 곱하여 $1 / 10$ 의 값으 로 스프링계수를 고려하였다. 즉, 처음의 경우는 $1.8 \mathrm{E}+06$ $\sim 5.0 \mathrm{E}+07 \mathrm{~N} / \mathrm{m}^{2}$ 의 범위를 대상으로 해저면 전단강성으로 보

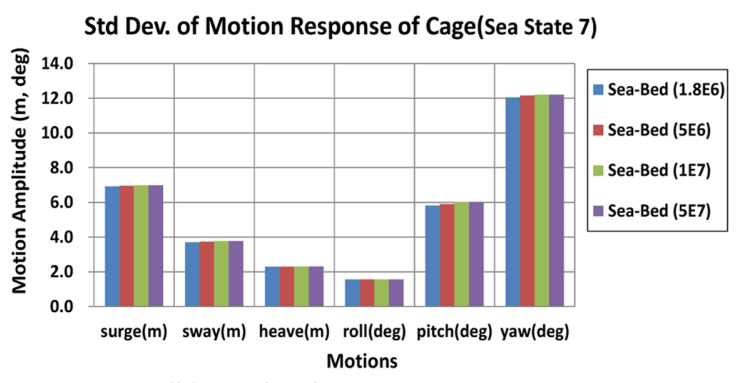

(b) std. dev. responses

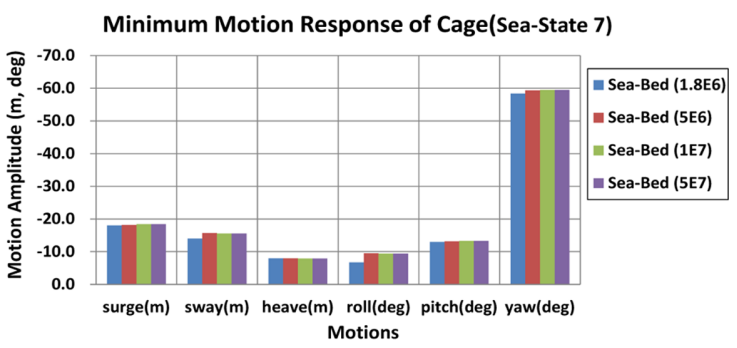

(d) min. responses

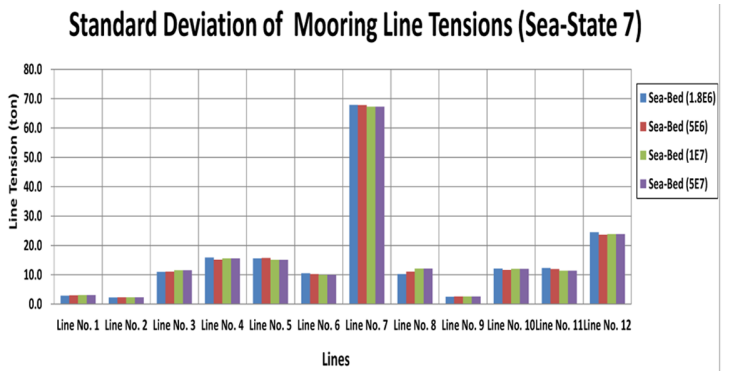

(b) std. dev. tensions

Minimum Mooring Line Tensions (Sea-State 7)

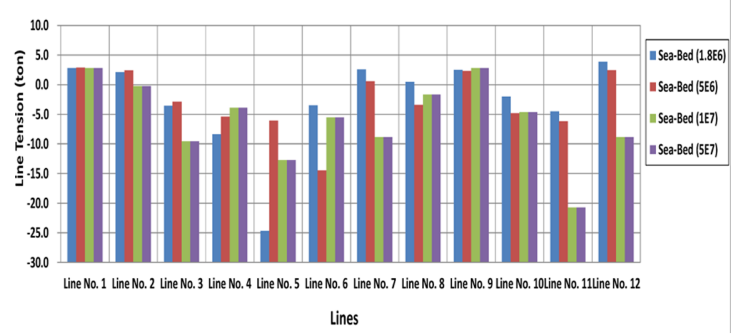

(d) min. tensions

Fig. 6. Mooring line tensions of the barge (Case 2). 


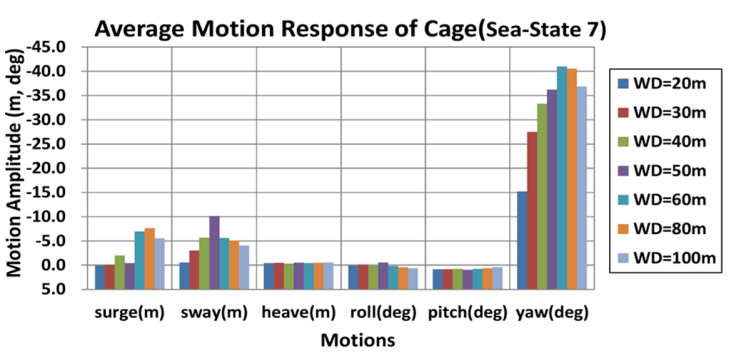

(a) average responses

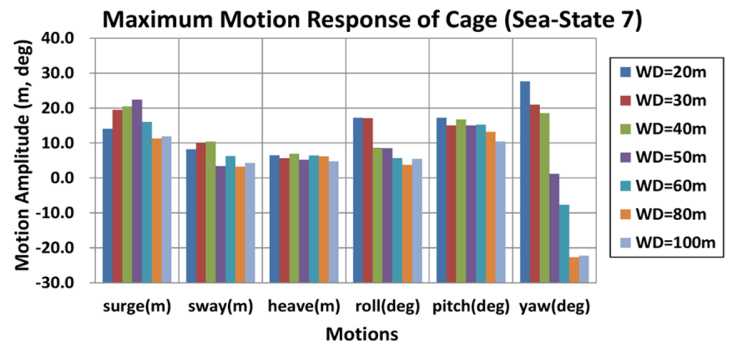

(c) max. responses

Fig. 7. Motion responses of the barge (Case 3).

Average of Mooring Line Tensions (Sea-State 7)

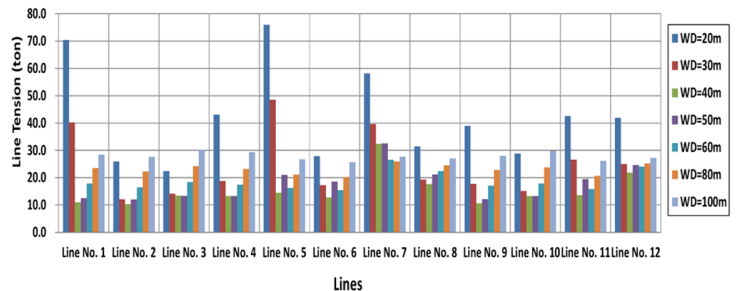

(a) average tensions

Maximum Mooring Line Tensions (Sea-State 7)

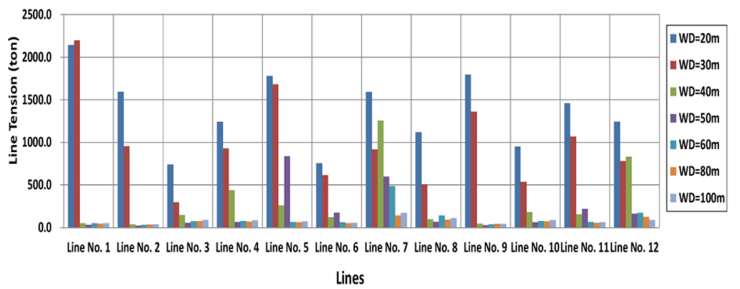

(c) max. tensions

Fig. 8. Mooring line tensions of the barge (Case 3).

고 해석조건으로 고려하였다. Fig. 5 6는 해석 수행 결과를 통계분석한 결과이다.

상기의 해석결과에서 보면 해저 바닥 강성이 바뀌더라도 부 유체의 운동에는 거의 영향을 주기 않지만 라인 장력에는 해 저바닥 강성이 클수록 최대 값과 최소 값이 작아지는 경향을 보이고 있다.

이를 통해 라인 장력에 불리하도록 해저바닥 강성을 작게, 즉 $2.1 \mathrm{E}+06$ 으로 간주하고 다음 해석 조건인 Case 3 의 해석 을 수행하였다. 해석조건 Case 3은 sea state 7에서의 천수효 과를 고려하기 위한 해석이다. Case 3의 Sea state 7인 경우 의 해석결과는 Fig. 7과 8에 보인다.

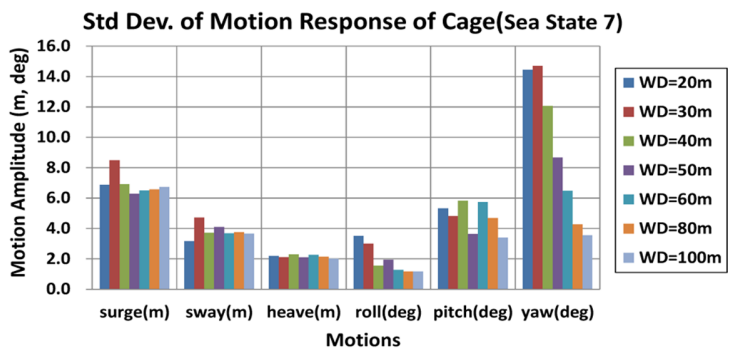

(b) std. dev. responses

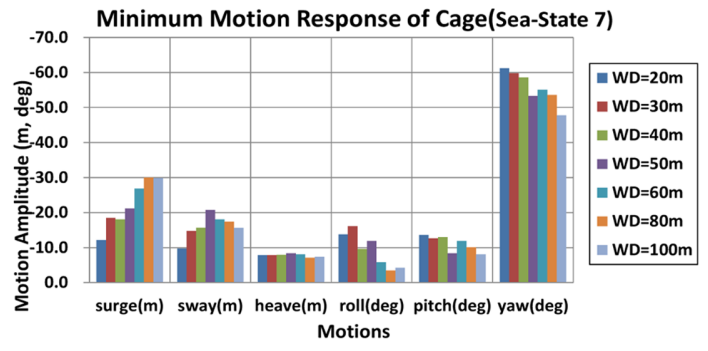

(d) min. responses

Standard Deviation of Mooring Line Tensions (Sea-State 7)

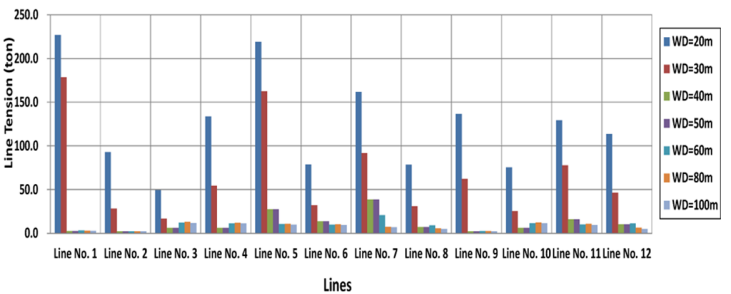

(b) std. dev. tensions

Minimum Mooring Line Tensions (Sea-State 7)

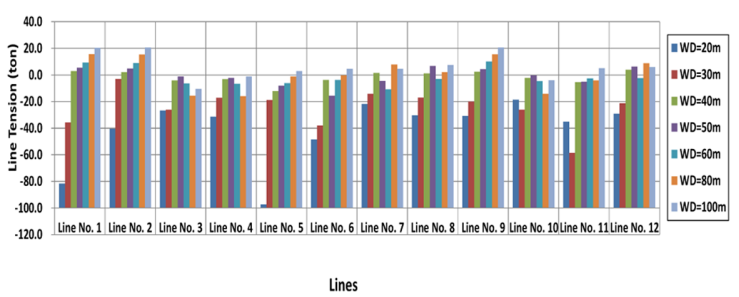

(d) min. tensions

상기의 Case 3의 해석결과 중 부유체의 운동 측면에서 보 면, 천수효과는 표준편차, 즉 동적 거동 특히 횡동요와 수평 회전운동에는 영향을 미치나 평균값, 즉 정적인 움직임에는 영향을 거의 영향을 미치지 않고 오히려 직선운동이나 수평 회전운도에는 유리한 영향을 미침을 알 수 있다. 라인장력 의 측면에서는 정적인 값과 동적인 값에 거의 절대적인 영 향을 미침을 알 수 있는데, $20 \mathrm{~m}$ 에서의 값과 $80 \mathrm{~m}$ 나 $100 \mathrm{~m}$ 일 때의 최대 값의 차이는 거의 10 배에서 40 배까지 차이가 나 타남을 알 수 있다. 최대값만을 보면 이러한 효과는 수심이 $60 \mathrm{~m}$ 일 때까지도 나타나서 $100 \mathrm{~m}$ 의 경우에 비해 $60 \mathrm{~m}$ 일 때 도 2.8 배, $50 \mathrm{~m}$ 일 때는 최대 11 배까지 나타남을 알 수 있다. 


\section{6. 결 론}

본 연구는 근해에 설치될 해양양식장을 바지형태로 단순화 하고 해상조건을 Sea-state 6 9까지로 가정하여 비교적 천해 역에 설치될 것을 가정하고, 해양양식장을 부유체 바지선으 로 수치모델화하여 동적 안전성해석 방법을 찾아보는 연구를 한 것이다. 이를 통해 천수 해역에 계류되었을 경우를 가상 하여 해저 바닥의 탄성 효과를 고려하여 계류라인과 부유체 의 연성된 동적 거동해석을 수행할 수 있도록 프로그램을 개 발하였다.

개발된 프로그램을 이용하여 천해역에서의 부유체 거동 해 석 가능성을 타진하기 위하여 부유된 바지선을 모델화하고 천해역의 기상조건을 가정하여 거동해석을 수행하였으며, 이 를 통해 (1) 계류라인의 길이효과, (2) 해저면 강성효과, (3) 해상조건에 따른 천수효과 등을 비교 검토해 볼 수 있었다. 결론적으로 정도의 검증이 있어야 하지만 부유체와 계류라 인 시스템에 미치는 천해역의 효과가 잘 드러나는 것을 확 인할 수 있었다. 개발된 프로그램을 활용한다면 천해역에 계 류된 부유체에 관한 동적 거동을 유효하게 해석할 수 있게 되었다.

\section{References}

API RP 2T. (1997). "Recommended Practice for Planning, Designing, and Consulating Tension Leg Platforms", $2^{\text {nd }}$ Ed., American Petroleum Institute, N.W., Washington D.C.

Dean, R.G. and Dalrymple, R.A. (1991). "Water Wave Mechanics for Engineers and Scientists", Advanced Seriesa on Ocean Engineering(Vol.2), World Scientific, 262-265.

http://www.rktl.fi/english/aquaculture/aquaculture_stations/laukaa_fish farm.html(2013.10.10.)

Kim, Y.B. (2003). "Dynamic Analysis of Multiple Body Floating Platforms Coupled with Mooring Lines", Thesis of Ph.D. in Ocean Engineering Devision of Texas A\&M university, 46-78.

Newman, J.N. (1998). "WAMIT (Ver. 5.4) User Manual", MIT, 3.5-3.27.

OCIMF(Oil Companies International Marine Forum) (1997). "Mooring Equipment Guideline ${ }^{\circ} \pm$, Report issued by OCIMF, 29-31.

PATRAN (2008). "User's Referemce Manual", MD PATRAN(2008 R1), 1-250.

Keoje Big Island PFV Ltd. Co. (2014). "The Report on the investigation of the Sea Bed Stiffness for the Exploration Project of Kohyun Habor Region", 75-78.

Received 3 August, 2015

1st Revised 9 September, 2015

2nd Revised 23 September, 2015

3nd Revised 5 October, 2015

Accepted 12 October, 2015 